\title{
VARIAÇÃO FONÉTICA DA VIBRANTE / / NA FALA PANKARARU: ANÁLISE DE FATORES LINGÜISTICOS
}

\section{Maria das Dores de Oliveira Universidade Federal de Alagoas (Doutoranda) /FUNAI (Professora)}

\section{Introdução}

A idéla da homogeneidade lingüística está bastante difundida na sociedade brasileira, embora os estudos lingüisticos venham contribuindo sistematicamente para desmistificar tal compreensão. lissa idéia de homogeneidade é passada sobretudo na escola. onde se privilegia uma variante lingüística - a norma padrão em detrimento das demais, o que $\mathrm{cm}$ contribuido para manter preconceitos linguiisticos.

MAIA (1986:9-10) diz que a elasticidade estrutural é uma das caracteristicas das linguas naturais. Tal propriedade, segundo essa autora, possibilita a variação na fala, permitindo que um mesmo enunciado seja pronunciado de diferentes maneiras. que soará dilierente conforme o contexto lingüistico e situacional, a procedência $1 \ldots+\cdots n a l$ e social. além das características fïsicas e até das disposições m.mmentâneas de cada falante. Nesse sentido. pode-se afirmar que a heterogencidade é uma característica inerente ao sistema lingüístico, porseste permute algumas variaçòes e proibe outras.

Na comunidade Pankararu, a escola tem fortemente contribuido para a permanência das disparidades entre o discurso que l. umpró e a situação lingüistica das crianças. haja vista que a prática redagóglea, no que se refere ao ensino de lingua portuguesa, não tem levado em conta a diferença, mas priorizado regras gramaticais como forma de garantrr o hem falar, objetwo que, sabemos, é dificil de ser atmendo. Tal fato tem servido de empecilho para que a escola possa desempenhar bem o seu papel, que é, entre outros, o de formar bons fentores e bons escritores e. também, o de educar para a vida. proncipalmente quando se sabe que, numa cultura especifica c hlerenciada da cultura dominante. a valorização dos aspectos sócio- 
culturais-religiosos da comunidade minoritária é extremamente importante para a manutenção dessa cultura.

Isso evidencia que é preciso que a escola compreenda o fenômeno da diversidade lingüística, reconhecendo as diferenças existentes entre a fala dos Pankararu e a norma padrão defendida por ela para poder ser coerente com uma perspectiva de escola que visa a formar os alunos para dentro e além dos limites da comunidade. Nessa perspectiva, pretendemos investigar a realização do fonema $/ \Gamma /$ na fala Pankararu. Estaremos observando a variação do ponto de vista lingüístico, ou de acordo com os fatores inerentes ao sistema lingüístico que favorecem ou não a variação.

\section{A comunidade indígena Pankararu}

A referência histórica mais antiga sobre os Pankararu data do início do século XVIII, quando tiveram os primeiros contatos com missionários que seguiram para o interior nordestino e se instalaram às margens do Rio São Francisco para organizar aldeamentos e conduzir os indios à conversão. ARRUTI (1996), em referência a HOHENTHAL (1960) afirma que o etnômio Pankararu é visto pela primeira vez em um relatório de 1702 e é citado junto a vários grupos indígenas: os Kararuzes (ou Cararus), os Tacarubas e os Poru, embora o aldeamento seja anterior a essa data. Posteriormente, em 1845, os Pankararu e os Poru aparecem novamente associados em mais outras duas aldeias localizadas em missões distintas. A quarta aldeia Pankararu localizada foi Brejo dos Padres, que hoje é a aldeia principal. Ela foi criada possivelmente no início do século XIX com o ajuntamento dos Pankararu, Poru, Umã, Vouves e Jeritacó (BARBALHO, 1988 vol.8 apud op.cit.).

A comunidade Pankararu atual está localizada no alto sertão pernambucano, nos municípios de Tacaratu, Petrolândia e Jatobá. Está distribuída em 17 aldeias, onde vivem cerca de $4.070^{1}$ indivíduos, que se agrupam em pequenos núcleos familiares e têm como base econômica a agricultura de subsistência (feijão, milho e mandioca), fruticultura (manga, caju, coco, goiaba, pinha etc.), pequenos criatórios, além de uma incipiente comercialização de produtos

De acordo com o censo realizado pela FUNASA-PE (Fundação Nacional de Saúde), em 2000. 
agricolas e artesanais. Há, ainda, alguns individuos que prestam serviços a terceiros e outros que são funcionários públicos.

Do território tradicional Pankararu, existem 8.100 hectares demarcados e homologados. Mesmo assim. continua invadido por posseiros que se instalaram no local há várias gerações. Estes, paulatinamente, estão sendo indenizados e retirados. A outra parte, 0.194 hectares, está identificada e em processo de reivindicação de posse.

Nos cinco séculos de contato com a sociedade nacional, este povo perdeu muitos traços de sua cultura. sendo uma das perdas a lingua ancestral, e há várias gerações expressam-se exclusivamente em português. No entanto, a adoção dos novos costumes não os impediu de continuar afirmando a identidade étnica, evidenciada sobretudo em alguns sinais diacríticos, como os rituais religiosos. Fistes são praticados corriqueiramente e são transmitidos de geração para geração.

No que concerne à educação institucionalizada, a comunidade é provida de onze escolas, sendo atendida em educação infantil e ensino fundamental de primeira à quarta série. A população estudantil assistida nas aldeias chega a mais de 800 alunos. Os professores, em sua grande maioria, são da própria etnia, havendo uns poucos vindos das cidades circunvizinhas.

\section{Observações teóricas e metodológicas}

Dado os objetivos do trabalho, a fundamentação teórica foi encontrada nos trabalhos de caráter descritivo do Português Brasileiro que visam a explicar a estrutura fonológica da lingua. Desse ponto de vista, revisamos uma parte da literatura disponivel, desde CÁMARA JR. (1991 e 1992), passando por MAIA (1986). MONARETTO et al. (1996). CAGLIARI (1997) e BORBA (1991). Buscamos também o apoio da teoria fonológica geral encontrada, principalmente, em GUSSENHOVEN e JACOBS (1998).

\subsection{A vibrante simples / $/$}

Uma longa discussão tem-se travado com relação ao estabelecimento do status da vibrante no sistema consonantal do Português. Marcado por um grande polimorfismo, este som tem fomentado muitos estudos e controvérsias. A questão é saber se há 
uma ou duas vibrantes. Alguns pesquisadores como Lopez, apud Monaretto et al. (1996), e Monaretto et al. (1996) defendem a idéia da existência de um único fonema com diferentes formas de realização. Outros autores, como Câmara Jr. (1992), assumem a idéia de que são dois fonemas vibrantes na língua portuguesa.

Nossa própria posição é a de que existem dois tipos de vibrantes: a vibrante simples ou tepe, como é também nomeada, $/ \mathrm{r} / \mathrm{e}$ a vibrante múltipla /r/, que, no dialeto Pankararu, é realizada como fricativa glotal surda, $[\mathrm{h}]$, produzida entre vogais e em inicio de vocábulos. Nos demais ambientes, prevalece a vibrante simples, que se realiza como $[\ulcorner],[\varnothing]$ ou $[\mathrm{h}]$.

O nosso principal argumento para optarmos pela tese de dois fonemas é a distinção fonológica entre eles em contexto intervocálico. Pois, como se sabe, esta é uma das características fundamentais de reconhecimento e identificação de um fonema, ou seja, que um par de segmentos semelhantes apresente um traço que os torne distinguiveis entre si. Nesse sentido, a hipótese das duas vibrantes parece ser pertinente.

Considerando a variação do $/ r /$ na comunidade Pankararu como uma variação contextual, buscaremos explicações teóricas que dêem conta do fenômeno. Nossa hipótese justifica-se a partir da observação de que nas falas dos informantes só em determinadas situações o / / / não sofre variação.

Os dados foram coletados através de entrevistas gravadas em áudio. O corpus selecionado foi composto por 16 informantes Pankararu de várias faixas etárias, moradores de diversas aldeias da comunidade. Nas entrevistas, procuramos fazer perguntas cujo conteúdo fosse do conhecimento e do interesse dos informantes. Os temas enfocados foram trabalho, festas e rituais da comunidade, atividades domésticas, lazer, esporte, escola, educação, histórias da aldeia. Incluímos também paródias, quando lidamos com crianças.

\section{Análise dos dados}

Para a análise procuramos, primeiro, definir o envelope de variação de cada variável. Em seguida, fizemos o encaixamento da variação no sistema considerando os seguintes fatores lingüísticos: 
tipo de silaba, posição acentual e segmentos precedente e seguinte. No conjunto de dados analisados, encontramos o fonema $/ \mathrm{r} /$ sendo realizado foneticamente como $[\varsigma],[h]$ ou sem realização fonética $[\varnothing]$, conforme já dissemos anteriormente. Representamos a situação no seguinte envelope de variação:

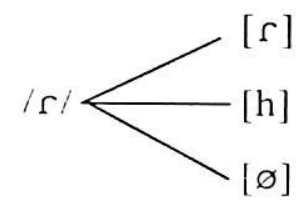

Ao estudarmos o padrão silábico da Língua Portuguesa e a distribuição do $/ \Gamma /$ no sistema, verificamos que, tendo em vista a análise do segmento precedente, interessava-nos observar o tipo de silaba $C_{1} C_{2} V$, em que o $/ \Gamma /$ é $C_{2}$ a segunda consoante de um onset complexo. Para analisar o segmento seguinte, verificamos que o padrão silábico que nos interessava era $\left(C_{1}\right)\left(C_{2}\right) V_{3}$, onde $C_{3}$ deveria estar seguida de uma sílaba iniciada por consoante.

O corpus com o qual trabalhamos, conforme já descrito anteriormente, foi analisado a fim de obtermos o quadro geral de variação do $/ \kappa /$. Para isto, cruzamos, desde o início da análise, os fatores lingüísticos tipo de silaba ou posição na sílaba - dado que em um tipo de sílaba, pelo menos, o tipo $\left(C_{1}\right)\left(C_{2}\right) \mathrm{VC}$, interessa observar se a posição do $C$ travando sílaba é medial $-\left(C_{1}\right)\left(C_{2}\right) \mathrm{V}-$. C - ou final $-\left(C_{1}\right)\left(C_{2}\right) \mathrm{V}-\#$.

A tabela 1, abaixo, mostra o quadro geral de realização do $/ \varsigma /$ no nosso corpus.

\section{Tabela 1}

Quadro geral de realização da variável

\begin{tabular}{|c|l|l|l|l|r|r|r|r|r|c|}
\hline & C-V & $\%$ & V-V & $\%$ & $(\mathrm{C})$ V-.C & $\%$ & (C)V-\# & \% & Subtot. & \% \\
\hline$[\ulcorner]$ & 2.543 & 68,67 & 2.907 & 100,0 & 366 & 33,18 & 18 & 0,64 & 5.834 & 55,54 \\
\hline$[\mathrm{h}]$ & - & - & - & & 642 & 58,20 & 59 & 2,11 & 701 & 6,67 \\
\hline$[\varnothing]$ & 1.160 & 31,33 & - & & 95 & 8,62 & 2.715 & 97,25 & 3.970 & 37,79 \\
\hline & 3.703 & & 2.907 & & 1.103 & & 2.792 & & 10.505 & \\
\hline
\end{tabular}




\subsection{Realização do fonema por tipo de sílaba e posição acentual}

Observando as realizações de $/ \mathrm{f} /$ em sílaba $[\mathrm{C} \quad \mathrm{V}]$. vemos que: a) o fonema / $/$ tem duas realizações alofônicas, $[\ulcorner]$ e $|\varnothing|$. neste dialeto, condicionadas lingüisticamente pelo fator acentuação: b) os monossílabos átonos e sílabas pós-tônicas favorecem o apagamento. ao passo que a realização de $[\ulcorner]$ prevalece nos outros tipos de acentuação silábica: monossilabos tônicos, silabas pré-tônicas e tônicas, conforme podemos ver na tabela II, abaixo.

\section{Tabela II}

Realização de / $/ \mathrm{e} / \mathrm{em}$ silaba [C_ $\mathrm{V}]$ de acordo com a posição acentual

\begin{tabular}{|l|r|r|r|r|r|r|}
\hline & \multicolumn{2}{|c|}{ Monossílabos } & \multirow{2}{*}{ Pré-tônica } & Tônica & Pós-tônica & Subtotais \\
\cline { 2 - 7 } & átono & tônico & & & & \\
\hline$[\ulcorner]$ & 413 & 91 & 1.025 & 779 & 235 & 2.543 \\
\hline$[\mathrm{h}]$ & - & - & - & - & - & - \\
\hline$[\varnothing]$ & 691 & - & 14 & 19 & 436 & 1.160 \\
\hline Total & 1.104 & 91 & 1.039 & 798 & 671 & 3.703 \\
\hline
\end{tabular}

O tipo de sílaba V-V, em que o/ $/$ / está em onset silábico, no meio da palavra, em posição intervocálica, não permite variação. Para qualquer tipo de acentuação, $/ \varsigma /$ realiza-se sempre como $[\varsigma]$. A regra aí é categórica, mesmo porque, sabemos, nesta posição há no sistema fonológico do Português uma oposição distintiva entre $/ r /$ e $/ r /$. A tabela abaixo serve apenas para reafirmar mais claramente essa observação.

\section{Tabela III}

Realização de / $/ \mathrm{l}$ em sílaba $\mathrm{V}-\mathrm{V}$ de acordo com a acentuação

\begin{tabular}{|c|c|c|c|c|c|c|}
\hline & \multicolumn{2}{|c|}{ Monossílabos } & \multirow{2}{*}{ Pré-tônica } & \multirow{2}{*}{ Tônica } & \multirow{2}{*}{ Pós-tônica } & \multirow{2}{*}{ Subtotais } \\
\hline & átono & tônico & & & & \\
\hline$[\Gamma]$ & - & - & 285 & 827 & 1.795 & 2.907 \\
\hline [h] & - & - & - & - & - & - \\
\hline$[\varnothing]$ & - & - & & & & \\
\hline Total & - & - & 285 & 827 & 1.795 & 2.907 \\
\hline
\end{tabular}


Em sílaba do tipo (C)V-.C os três alofones de $/ \Gamma /$ são encontrados: $[\varsigma],[h]$ e $[\varnothing]$. É evidente que, por precisarmos observar palavras de duas sílabas ou mais, já que o fonema $/ \Gamma /$ é aqui considerado em travamento silábico no meio da palavra, o fenômeno a ser tratado neste ponto não ocorre em monossílabos. Assim, deveríamos observar as situações em que o fonema aparecia em sílaba pré-tônica, tônica ou pós-tônica. E, nesse caso, a sílaba pré-tônica permite um envelope de variação mais amplo, predominando a realização do alofone $[\mathrm{h}]$, seguido de $[r]$ e, em menor proporção. da variante [ø]. As demais posições acentuais apresentam um envelope mais reduzido de variação: na silaba tônica, ocorrem apenas $[\kappa] \mathrm{e}[\mathrm{h}]$ : na posição pós-tônica, a variação quase não ocorre.

Os dados estão expostos na tabela IV, abaixo.

\section{Tabela IV}

Realização de / r/ em sílaba (C)V-.C de acordo com a acentuação

\begin{tabular}{|c|c|c|c|c|c|c|}
\hline & \multicolumn{2}{|c|}{ Monossílabos } & \multirow{2}{*}{ Pré-tônica } & \multirow{2}{*}{ Tônica } & \multirow{2}{*}{ Pós-tônica } & \multirow{2}{*}{ Subtctais } \\
\hline & átono & tônico & & & & \\
\hline$[\ulcorner]$ & - & 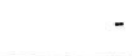 & 305 & 60 & 01 & 366 \\
\hline$[\mathrm{h}]$ & - & - & 377 & 265 & - & 642 \\
\hline [ø] & - & - & 95 & - & - & 95 \\
\hline Total & - & - & 777 & 325 & 01 & 1.103 \\
\hline
\end{tabular}

A variação de $/ \mathrm{S} /$ no tipo de silaba $(\mathrm{C}) \mathrm{V}$ - \#, considerando o acento da sílaba, mostra que o fonema $/ \mathrm{r} /$ em coda silábica final de palavra, é preponderantemente representado por [ø], ou seja, todo o material fonético é apagado nesta posição. A regra nesse caso, tem a seguinte formulação:

$$
/ \mathrm{Sl} \quad \rightarrow \quad[\varnothing] \quad /(\mathrm{C}) \mathrm{V}-\#
$$

Essa regra pode ser lida assim: o fonema $/ \varsigma /$ é apagado quando aparece na coda de uma sílaba do tipo (C)V-\#.

$$
\text { [sī'joø] "senhor" }
$$


A tabela $V$ mostra a variação de $/ \delta /$ nesse ambiente, considerando-se a acentuação da sílaba.

\section{Tabela V}

Realização de / $/$ / em sílaba (C)V-\# de acordo com a acentuação

\begin{tabular}{|l|r|r|r|r|r|r|}
\hline & \multicolumn{2}{|c|}{ Monossílabos } & \multirow{2}{*}{ Pré-tônica } & Tônica & Pós-tônica & Subtotais \\
\cline { 2 - 5 } & átono & tônico & & 05 & 02 & 18 \\
\hline$[\ulcorner]$ & 10 & 01 & - & 05 & 02 & 59 \\
\hline$[\mathrm{h}]$ & 45 & 11 & - & 01 & 08 & 2.715 \\
\hline$[\varnothing]$ & 24 & 485 & - & 2.198 & 12 & 2.792 \\
\hline Total & 79 & 497 & - & 2.204 & 12 & \\
\hline
\end{tabular}

A observação por tipo de acento da sílaba em que a variável se encontra permite fazer as seguintes constatações:

a) estatisticamente, há um número maior de ocorrências desse fonema na sílaba tônica;

b) do mesmo modo, também é nos monossílabos tônicos que aparece o maior número de ocorrências;

c) as constatações (a) e (b) acima, podem ser justificadas se observarmos que todas as formas infinitivais de verbos terminam por $/ \mathrm{r} / \mathrm{e}$ todas as formas verbais infinitivais são arrizotônicas, quer dizer, o acento mais forte recai sobre as desinências e não sobre a raiz. No caso específico, o acento forte recai sobre a vogal temática, à qual agrega-se silabicamente o $/-\Gamma /$, desinência de infinitivo. Entretanto. ¿ bom lembrar que essa predominância de $/ \Gamma /$ na forma infinitival dos verbos não significa que se possa afirmar categoricamente que se apaga a desinência de infinitivo. O fato é fonológico, pois o que se apaga é o fonema $/ \Gamma /$, independente da categoria e subcategoria da palavra;

d) com relação ao número de ocorrências do fonema em sílabas tônicas, monossílabos e outros, é também nessas posições que ocorre o maior número de apagamentos, tanto em monossílabos tônicos, como em sílaba tônica em palavras con duas ou mais sílabas. 
Poderíamos dizer que essa é uma regra categórica, se considerássemos que os casos de não aplicação são devidos a fenômenos outros, como juntura externa - a palavra seguinte começa por vogal - e processos de redução de vocábulo fonológico, quando o fonema sai da fronteira de palavra e aproxima-se de um segmento seguinte que tende a mantê-lo ou a realizá-lo como um dos seus alofones.

\subsection{Realização do fonema de acordo com segmentos precedente e seguinte}

Para observar as realizações do fonema de acordo com o segmento precedente só um tipo de sílaba, o tipo $\mathrm{C}-\mathrm{V}$. iria interessarnos, visto que qualquer vogal precedente não parece influenciar a realização do fonema.

Os segmentos que podem preceder $/ \varsigma /$, em Português, o que significa dizer que só estes segmentos formam onsets complexos com $/ \mathrm{r} /$, são $/ \mathrm{p}, \mathrm{b}, \mathrm{t}, \mathrm{d}, \mathrm{k}, \mathrm{g}, \mathrm{f}, \mathrm{v} /$. Para todos eles, encontramos ocorrências de apagamento da vibrante. Os números mais significativos de apagamentos ocorreram $\operatorname{com} / \mathrm{p} /$, seguido de $/ \mathrm{t} / \mathrm{d} / \mathrm{d} / \mathrm{e}$ $/ \mathrm{v} /$. Os segmentos $/ \mathrm{k} / \mathrm{.} / \mathrm{g} / \mathrm{e} / \mathrm{f} /$ foram os que apresentaram o menor número de ocorrências de apagamento da vibrante simples. O segmento /b/ também apresentou um indice relativamente baixo de ocorrência de apagamento de $/ \varsigma /$. Os resultados aparecem abaixo, na tabela VI.

\section{Tabela VI}

Quadro geral de ocorrência das variantes de acordo com o segmento precedente

\begin{tabular}{|l|r|r|r|r|r|r|r|r|c|}
\hline & $\mathrm{p}$ & $\mathrm{b}$ & $\mathrm{t}$ & $\mathrm{d}$ & $\mathrm{k}$ & $\mathrm{g}$ & $\mathrm{f}$ & $\mathrm{v}$ & \multicolumn{1}{c|}{ Total } \\
\hline$[\ulcorner]$ & 1.000 & 351 & 565 & 69 & 210 & 160 & 68 & 16 & 2.439 \\
\hline$[\mathrm{h}]$ & - & - & - & - & - & - & - & - & - \\
\hline$[\varnothing]$ & 719 & 57 & 332 & 35 & 03 & 08 & 01 & 17 & 1.172 \\
\hline Totais & 1.719 & 408 & 897 & 104 & 213 & 168 & 69 & 33 & 3.611 \\
\hline
\end{tabular}


Observando-se as ocorrências de $[\ulcorner]$ e [ø], podemos dividir os segmentos em três classes: 1) oclusivas anteriores, /p, b, 1, d/: 2) oclusivas posteriores, $/ \mathrm{k}, \mathrm{g} / ;$ e 3 ) fricativas labiais, /f, $\mathrm{v} /$. Considerando, ainda, que $/ \delta /$ é o fonema, ou a sua representação subjacente, e [ø] a realização de superficie, condicionada pelo segmento precedente, vemos que as oclusivas anteriores favorecem a aplicação da regra que apaga $/ \Gamma /$ nesses contextos. As oclusivas posteriores e fricativas labiais permitem aplicação da regra, que é do tipo variável, mas não a favorecem. Isso pode ser melhor observado olhando-se o quadro I, a seguir.

\section{Quadro I}

Classes de consoantes que ocorrem antes da vibrante $/ \mathrm{f} / \mathrm{em}$ onsets complexos

\begin{tabular}{|l|c|c|c|c|c|c|}
\hline & \multicolumn{4}{|c|}{ anteriores } & \multicolumn{2}{c|}{ posteriores } \\
\hline & \multicolumn{2}{|c|}{ labiais } & \multicolumn{2}{c|}{ alveolares } & \multicolumn{2}{c|}{ velares } \\
\hline & surdas & sonoras & surdas & sonoras & surdas & sonoras \\
\hline oclusivas & $\mathrm{p}$ & $\mathrm{b}$ & $\mathrm{t}$ & $\mathrm{d}$ & $\mathrm{k}$ & $\mathrm{g}$ \\
\hline fricativas & $\mathrm{f}$ & $\mathrm{v}$ & & & & \\
\hline
\end{tabular}

Se observarmos mais de perto, desta vez separando as oclusivas anteriores em duas novas classes, temos que: 1) oclusivas anteriores surdas, /p, t/, são mais sensíveis à aplicação da regra de apagamento; 2) oclusivas anteriores sonoras, /b, d/, são menos sensíveis a sua aplicação.

A regra, então, pode ser formulada como segue:

$$
\begin{array}{rl|l|}
|\Gamma| \rightarrow|\varnothing| & \mathrm{C}-\left(\begin{array}{l}
\text {-cont. } \\
\text { tanterior } \\
-\mathrm{voz}
\end{array}\right)
\end{array}
$$


Leitura da regra: a variável / $/$ passa a [ø] depois de uma consoante [-continuante. +anterior. -voz] no onset silábico complexo.

Considerando-se o segmento seguinte também, as três realizaçōes foram encontradas. Tivemos, porém. diferente do que acontece quando se leva em conta os 04 tipos de sílabas, um número malor de ocorrèncias de $[\mathrm{h}]$. seguido de $[\ulcorner]$. O apagamento[ø] teve un indice menor de ocorrência. Esses dados podem ser lidos na tabela abaixo:

\section{Tabela VII}

Quadro geral de ocorrência das variantes de acordo com o segmento seguinte

\begin{tabular}{|l|r|r|r|r|r|r|r|r|r|r|r|r|r|r|r|} 
& $\mathrm{p}$ & $\mathrm{b}$ & $\mathrm{t}$ & $\mathrm{d}$ & $\mathrm{k}$ & $\mathrm{g}$ & $\mathrm{f}$ & $\mathrm{v}$ & $\mathrm{s}$ & $\mathrm{z}$ & 3 & $\mathrm{l}$ & $\mathrm{m}$ & $\mathrm{n}$ & total \\
\hline$|\mathrm{f}|$ & - & - & 01 & - & 227 & 17 & 02 & 30 & 50 & - & 27 & - & 16 & - & 370 \\
\hline$[\mathrm{h}]$ & 01 & 04 & 217 & 113 & 67 & 20 & - & 09 & 26 & 01 & 01 & 01 & 103 & 77 & 640 \\
\hline $\mid \varnothing]$ & - & - & - & - & 89 & 01 & - & 01 & - & 04 & - & - & - & - & 95 \\
\hline Totais & 01 & 04 & 218 & 113 & 383 & 38 & 02 & 40 & 76 & 05 & 28 & 01 & 119 & 77 & 1.105 \\
\hline
\end{tabular}

$\mathrm{O}$ alofone $[\mathrm{h}]$ foi favorecido pela proximidade com os segmentos seguintes $/ \mathrm{t} /, / \mathrm{d} /, / \mathrm{g} / . / \mathrm{m} / \mathrm{e} / \mathrm{n} /$. O alofone $[\mathrm{r}$ ] ocorreu mais vezes diante do segmento $/ \mathrm{k} /$, seguido de $/ \mathrm{v} /, / \mathrm{s} /$, e $/ 3 /$. Embora o apagamento diante de $/ \mathrm{k} /$ não tenha sido predominante, foi nesse ambiente que houve maior ocorrência. $O$ alofone $[h]$ foi o menos produzido. Assim, as três regras que podem ser formuladas a partir dessa análise das realizações de $/ \Gamma /$ de acordo com o segmento scenunte só podem ser mais ou menos generalizadas:

A promerra generalização permite-nos dividir os segmentos encontrados no contexto considerado em duas grandes classes: orais e nanils. As consoantes orais podem ser subdivididas em duas classes: oclusisas e firicativas. respectivamente -continuante e +continuante 2 . $1: m$ regurda, as oclusivas podem ser separadas em termos de ponto de articulação: labiais, alveolares e velares. As fricativas, por esse mesmo

\io consideramos nesta análise a lateral / devido a sua presença nos dados. um único caso nessa posição, ser considerada irrelevante. 
critério, dividem-se em labiais, alveolares e palatais. Além disso, à exceção das nasais, cuja sonoridade é inerente. os segmentos são reclassificados em surdas e sonoras -- - $\mathrm{voz} \mathrm{c}+\mathrm{voz}$. Apresentamos uma sintese dessa discussão no quadro III, a seguir.

\section{Quadro II}

Classes de consoantes que ocorrem depois da vibrante $/ \mathrm{f} / \mathrm{em}$ silaba (C) $\mathrm{V}-\mathrm{C}$

\begin{tabular}{|l|l|l|c|c|c|c|}
\hline \multicolumn{2}{|c|}{} \\
\hline \multirow{3}{*}{ orais } & oclusivas & surdas & labiais & alveolares & palatais & velares \\
\cline { 3 - 7 } & & sonoras & $\mathrm{b}$ & $\mathrm{t}$ & & $\mathrm{d}$ \\
\cline { 3 - 7 } & fricativas & surdas & $\mathrm{f}$ & $\mathrm{s}$ & & $\mathrm{g}$ \\
\cline { 3 - 7 } & & sonoras & $\mathrm{v}$ & $\mathrm{z}$ & 3 & \\
\hline nasais & & & $\mathrm{m}$ & $\mathrm{n}$ & & \\
\hline
\end{tabular}

As oclusivas labiais e alveolares desfavorecem a realização do fonema como $[\ulcorner]$. Encontramos apenas uma ocorrência de $[\kappa]$ antes de $/ \mathrm{t} /$. As oclusivas velares $/ \mathrm{k}, \mathrm{g} /$ favorecem a aplicação da regra.

$\mathrm{Na}$ classe das fricativas, tanto é menos freqüente essa distribuição de $/ \delta /$, como é mais difícil generalizar a regra de aplicação. Entre as labiais, a freqüência de $[\ulcorner]$ diante da surda /f/ é insignificante, enquanto que diante da sonora $/ \mathrm{v} /$, a freqüência é mais alta, sendo maior também o favorecimento da aplicação da regra.

Entre as alveolares, a freqüência do alofone $[\ulcorner]$ é bastante reduzida. Apenas diante da surda /s/, a regra foi aplicada. Do mesmo modo, das palatais, somente a sonora /3/ apareceu depois de $|r|$. favorecendo a regra de uma forma quase categórica. A classe das nasa1s mostrou-se extremamente desfavorável à aplicação dessa regra. Apenas a labial $/ \mathrm{m} /$ teve umas poucas aplicações.

A realização de / $/$ / como [h] de acordo com o segmento seguinte mostrou-se favorecida pelas seguintes classes: oclusivas alveolares e nasais, onde a regra foi aplicada quase categoricamente. 
O apagamento de /r/ de acordo com o segmento seguinte, teve um número alto de realizações diante de $/ \mathrm{k} /$. Esse número, porém. parecé-nos não muito revelador quanto ao favorecimento da regra a este segmento, dado que tivemos um único vocábulo - porque - em todas as aplicações.

\section{Conclusão}

Neste trabalho apresentamos algumas características da fala Pankararu. Considerando o contexto lingüistico, procuramos sistematizar as formas de realizações do fonema $/ r /$. Pudemos perceber que os padrões tradicionais de realização desse fonema ainda são vigentes na comunidade. Contudo, as outras variantes aparecem predominantemente em contextos que as favorecem.

A variação em relação ao fonema / $/$ revelou-se dificil de ser descrita e interpretada, tendo em vista que fatores diversos, de caráter lingüístico, como posição na sílaba e na palavra. e acentuação, e, em menor escala, os segmentos circundantes, concorrem para esta variação. que é extremamente árdua de ser sistematizada, sobretudo quando se cruzam os diferentes tipos de fatores.

Esperamos que esse nosso estudo, embora bastante pontual, possa contribuir para reforçar a importância da pesquisa lingüística no contexto escolar e alertar os profissionais da educação para que observem a riqueza das variações lingüísticas e os condicionantes sociais, históricos e lingüísticos dos alunos. Assim, esses profissionais poderão ampliar seus conhecimentos e desenvolver atitudes condizentes com a escola que cada comunidade quer ou precisa.

A escola não pode fícar alheia à variação lingüística. No nosso trabalho, vimos como o apagamento de /r/final, que é um problema sério para a aprendizagem da língua escrita padrão, revelou-se uma regra quase categórica na fala Pankararu. É preciso refletir, e chamar os professores a refletirem junto, sobre isso. 


\section{REFERÊNCIAS BIBLIOGRÁFICAS}

ARRUTI, J. M. P. A. Oreencantamento do mundo. Trama Histórica e Arranjos Territoriais Pankararu. Dissertação de Mestrado. Rio de Janeiro: UFRJ/Museu Nacional, 1996.

BARBALHO, N. Cronologia pernambucana: subsídios para a história do agreste e do sertão. Fundação de Desenvolvimento Municipal do Interior de Pernambuco, vol. 16. Recife, 1982-1988.

BORBA. F. S. Introdução aos estudos lingiüisticos. Campinas: Pontes, 1991 .

CA(il.tari. L. C. Análise fonológica: introduçào à teoria è prática com expecial destaque ao modelo fonemico. Campinas: Edição do Autor, 1997.

CÂMARA JR., J. M. Problemas de lingüistica descritiva. Petrópolis: Vozes, 1991.

CÂMARA JR., J. M. Estrutura da lingua portuguesa. Petrópolis: Vozes, 1992.

GUSSENHOVEN, C. e JACOBS, H. 1998. Understanding phonology. London: Arnold, 1998.

HOHENTHAL JR., W. D. As tribos indígenas do médio e baixo São Francisco. Revista do Museu Paulista (Nova série, vol.XII). São Paulo. 1960.

I.EMLE, M. Heterogeneidade dialetal: um apelo à pesquisa. Tempo Brasileiro. Rio de Janeiro, 53-54, abr./set. 1978.

MAIA, E. M. No reino da fala. São Paulo: Ática, 1986.

MONARETTO, V. N. O. et al. As consoantes do Português. In: I.. BISOL (org.). Introdução a estudos de fonologia do português brasileiro. Porto Alegre: EDIPUCRS, 205-246, [s.d.].

OLIVEIRA, M. D. Variação fonética da vibrante It lua fala Pankararu. Análise lingüistica e sociolingüiistica. Dissertação de Mestrado. Maceió: Universidade Federal de Alagoas. Centro de Ciências Humanas, Letras e Artes, Programa de Pós-Graduação em L.etras e Lingüistica, 2001. 